\title{
Liver Cancer pT0 TNM Finding v7
}

National Cancer Institute

\section{Source}

National Cancer Institute. Liver Cancer pTO TNM Finding v7. NCI Thesaurus. Code C90158.

Liver cancer with no evidence of a primary tumor. (from AJCC 7th Ed.) 